\title{
Evaluating changes in catchment-scale evapotranspiration after $50 \%$ thinning in a headwater catchment
}

\author{
Chen-Wei Chiu ${ }^{1}$, Takashi Gomi ${ }^{1}$, Marino Hiraoka ${ }^{2}$, Katsushige Shiraki ${ }^{3}$, Yuichi Onda ${ }^{4}$, and \\ Bui Dung 5
}

${ }^{1}$ Tokyo University of Agriculture and Technology

${ }^{2}$ Public Works Research Institute

${ }^{3}$ Tokyo univ. of Agri. \& Tech.

${ }^{4}$ University of Tsukuba

${ }^{5}$ Vietnam National University of Forestry

January 20, 2022

\begin{abstract}
We examined changes in catchment-scale annual and seasonal evapotranspiration after $50 \%$ strip thinning, using runoff data from headwater catchments. The short-term water balance (STWB) method between periods from 8 to 100 days was applied to the treated $\left(\mathrm{K}_{\mathrm{T}}\right)$ and control $\left(\mathrm{K}_{\mathrm{C}}\right)$ catchments. The estimated evapotranspiration during the pre- and post-thinning periods were 840 and 910 and 780 and $860 \mathrm{~mm} /$ year in the catchments $\mathrm{K}_{\mathrm{T}}$ and $\mathrm{K}_{\mathrm{C}}$, respectively. According to a paired catchment analysis of estimated evapotranspiration, monthly evapotranspiration increased from 3 to $20 \mathrm{~mm}$ from June to December, while it decreased from 7 to $31 \mathrm{~mm}$ from January to May. The estimated annual and monthly evapotranspiration was compatible with the values monitored in the plot-scale interception, canopy transpiration, and ground surface evapotranspiration. Our findings showed that the decreases in evapotranspiration due to $50 \%$ thinning were similar or different in different methods of measurement when compared with thinning in the other catchments around the world. The STWB model can evaluate the effects of timber harvesting on changes in evapotranspiration (ET), including the reproduction of seasonal patterns of ET.
\end{abstract}

\section{Hosted file}

Chiu et al. (HP)_main documentV3.docx available at https://authorea.com/users/369493/ articles/553447-evaluating-changes-in-catchment-scale-evapotranspiration-after-50thinning-in-a-headwater-catchment

\section{Hosted file}

Tables.docx available at https://authorea.com/users/369493/articles/553447-evaluatingchanges-in-catchment-scale-evapotranspiration-after-50-thinning-in-a-headwater-catchment 

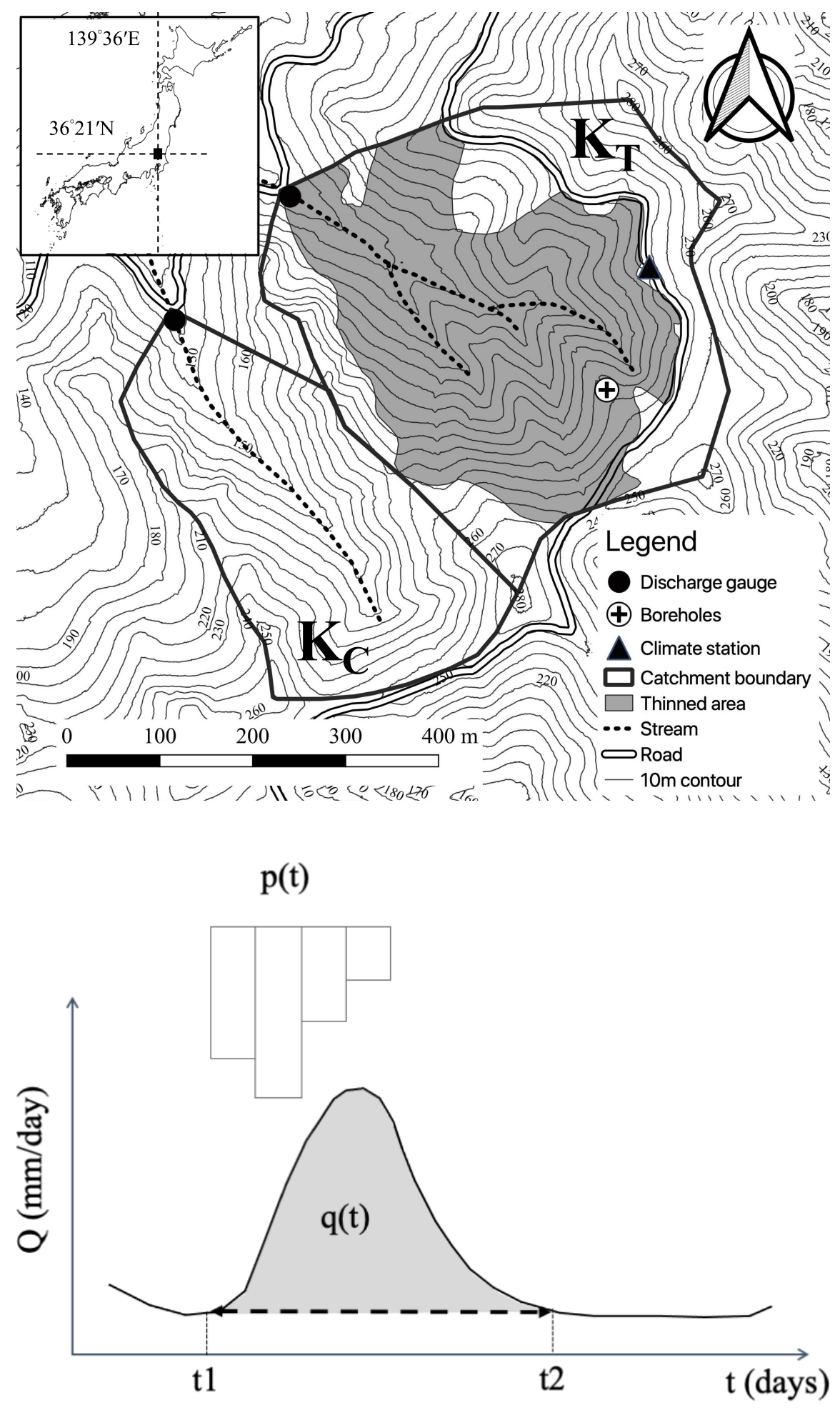

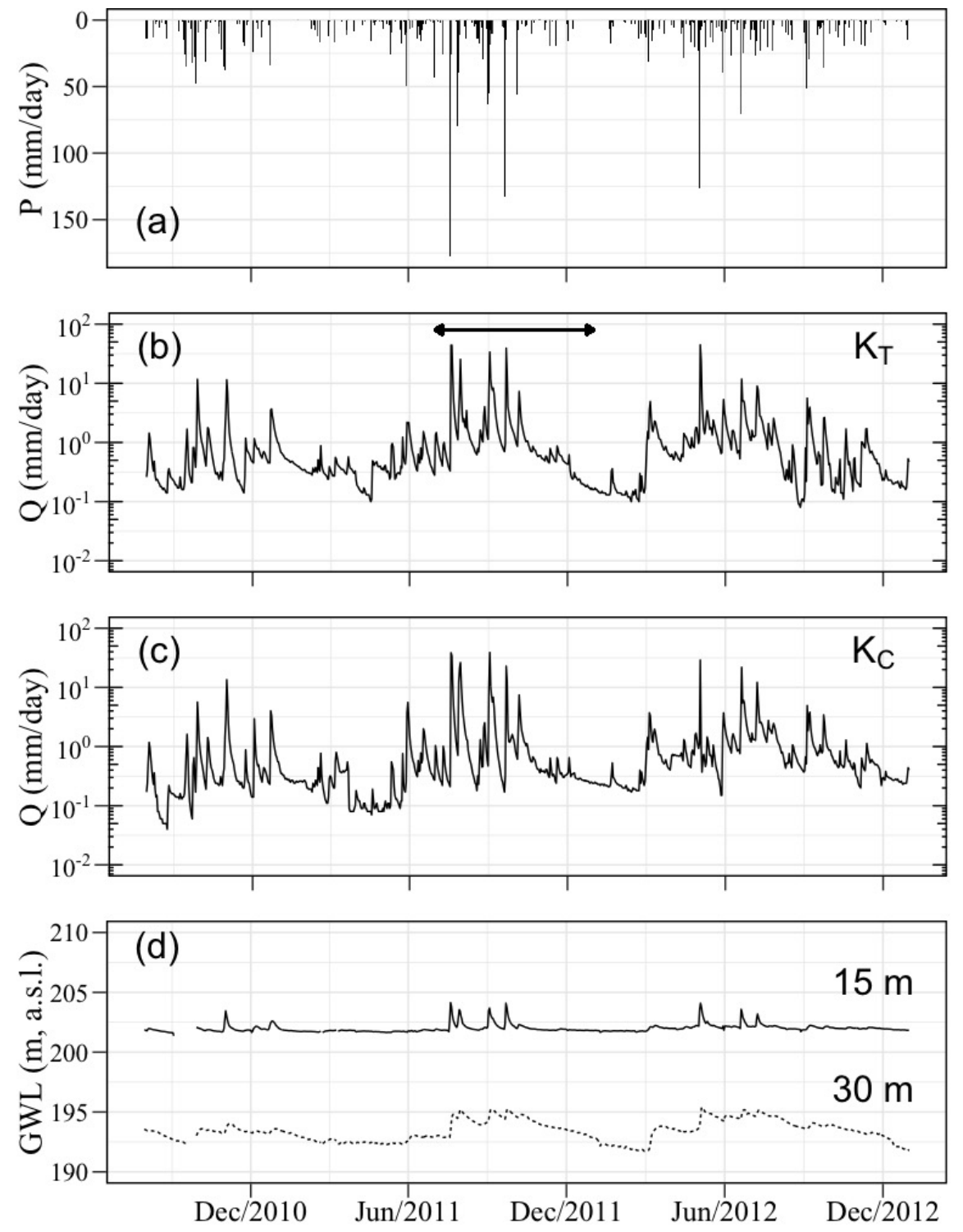

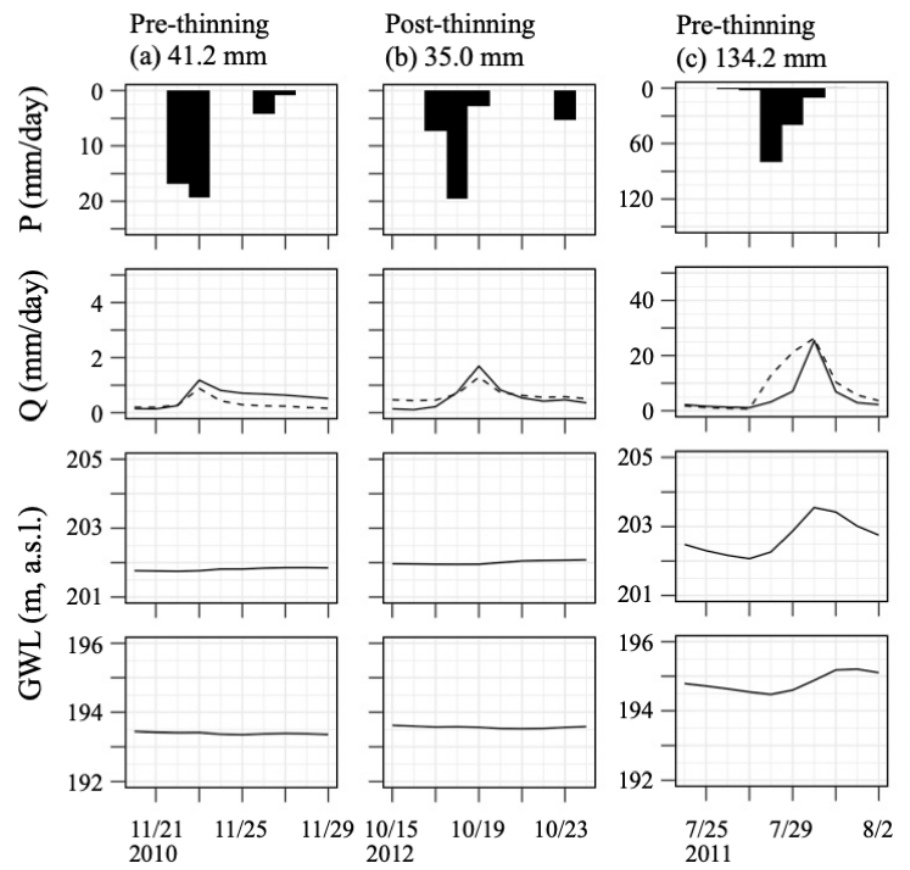

Post-thinning

(d) $167.8 \mathrm{~mm}$
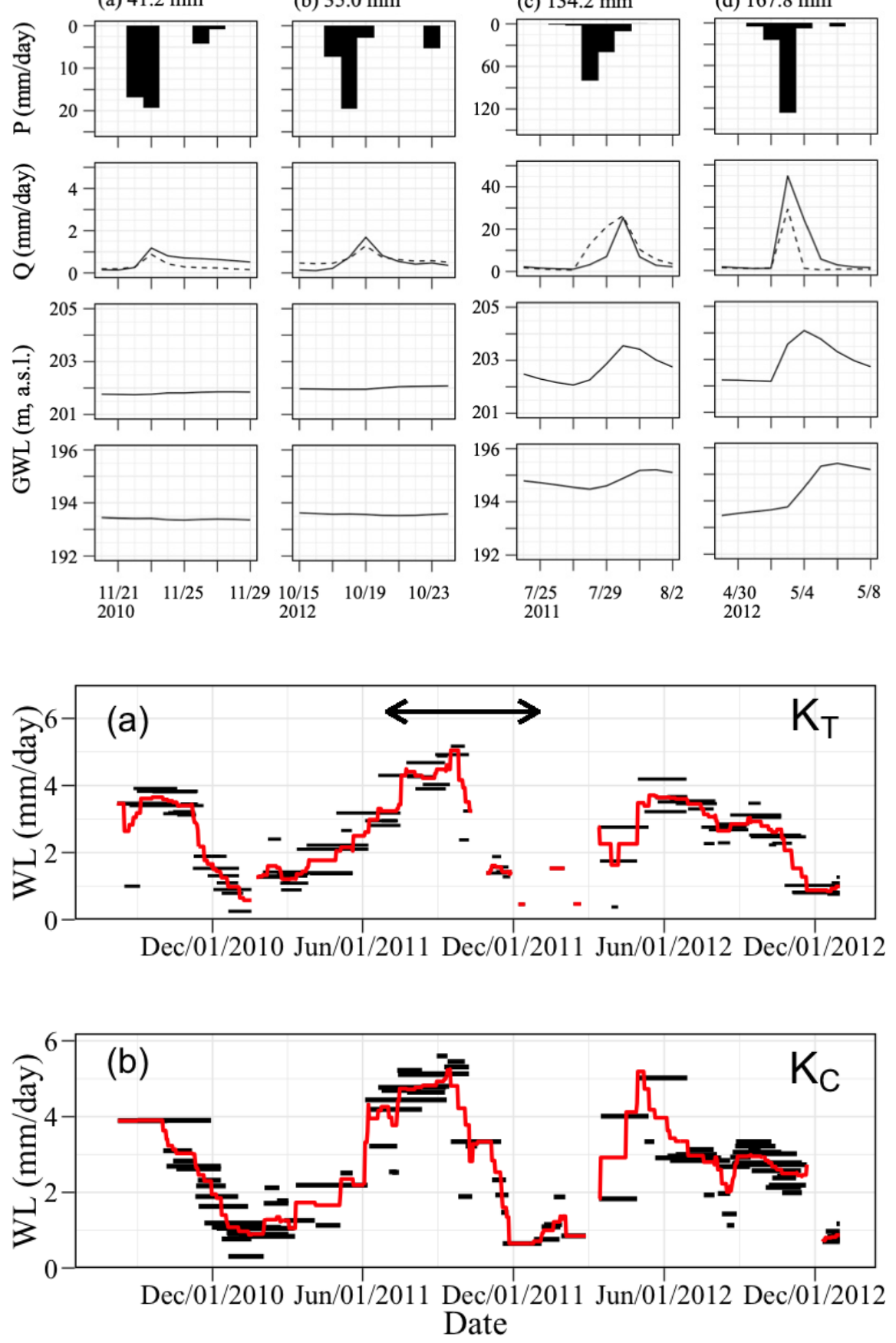

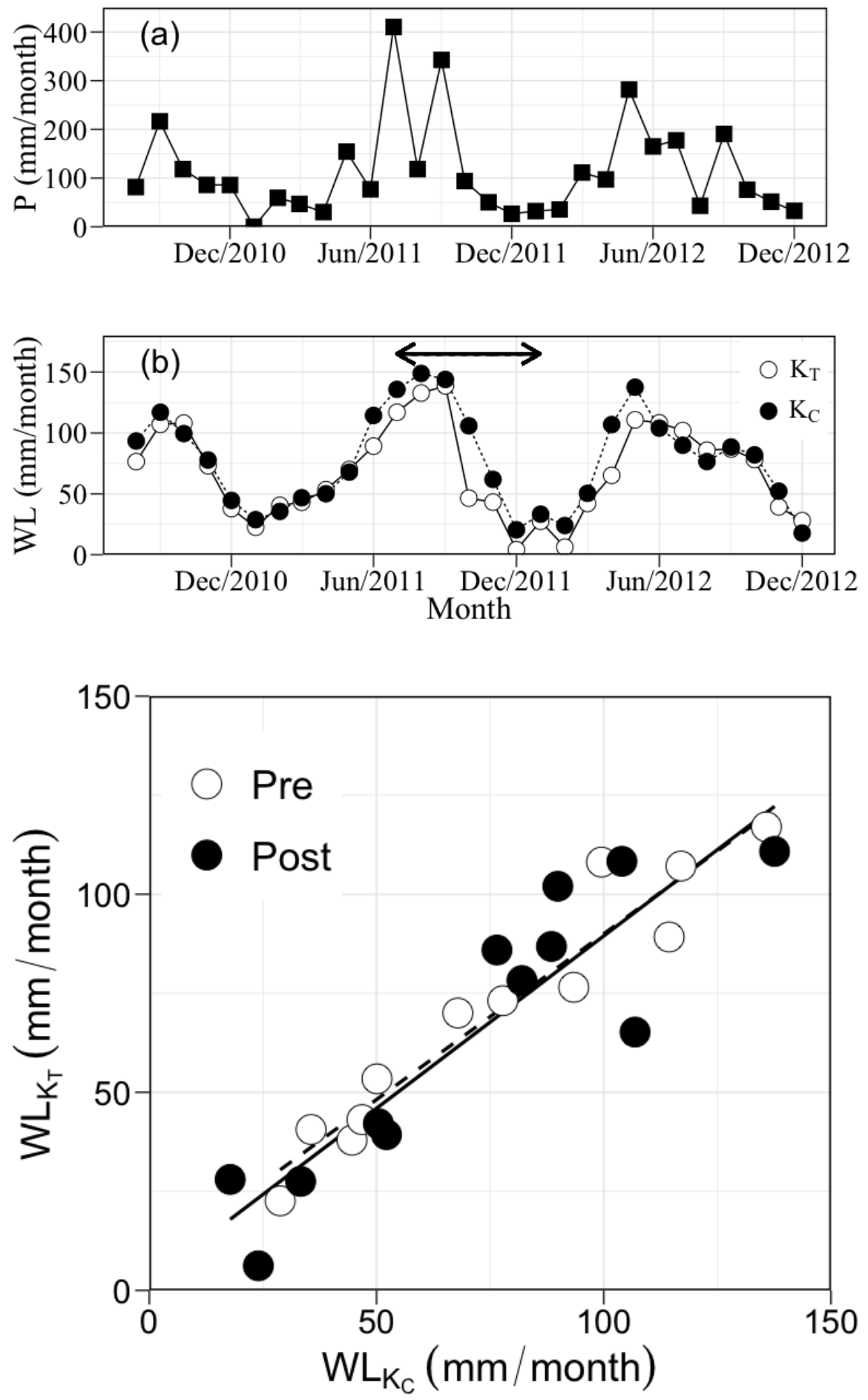


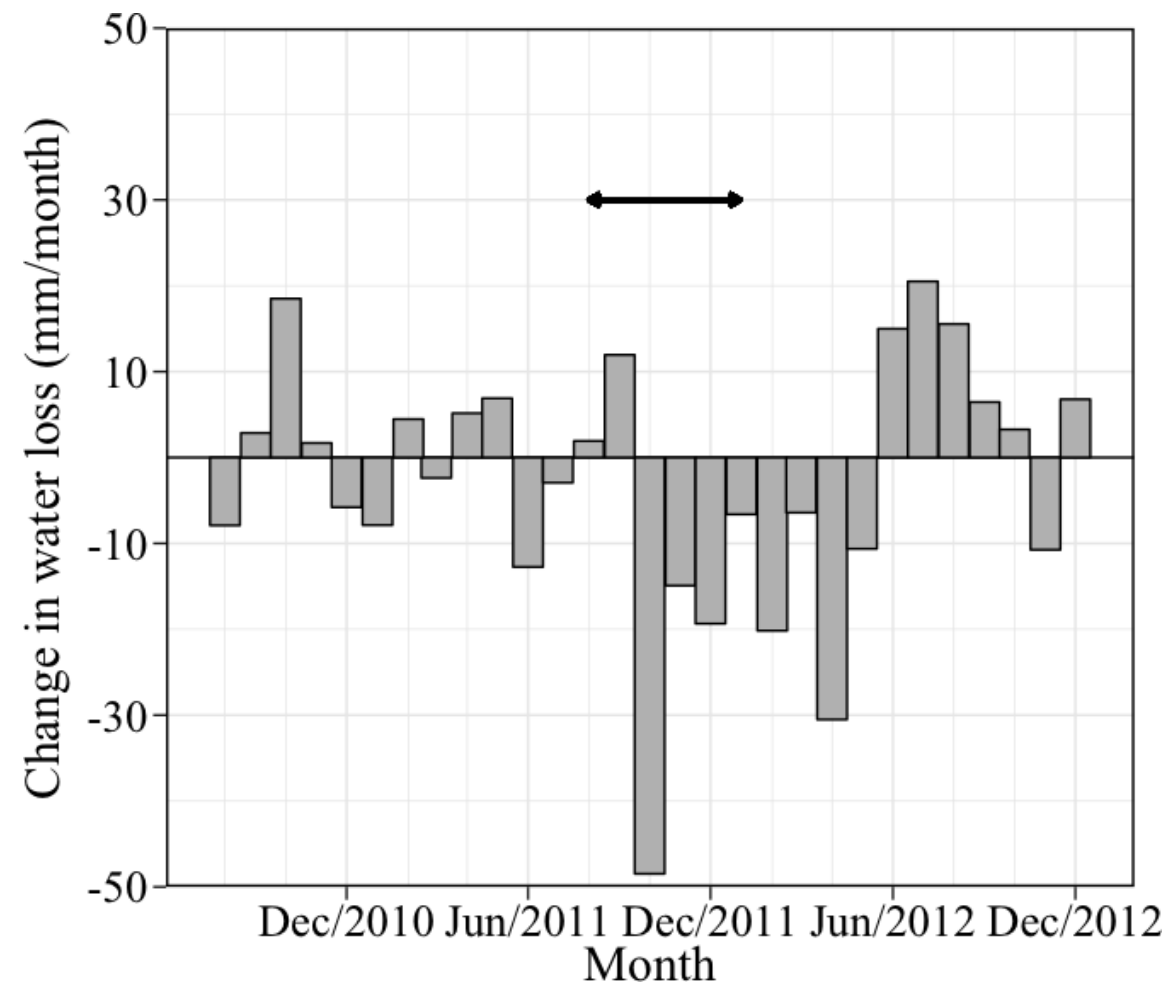

